\title{
Sexual violence within marriage: A case study of rural Uttar Pradesh
}

\author{
M.E. Khan \\ Population Council \\ John Townsend \\ Population Council \\ Ranjana Sinha \\ Seema Lakhanpal
}

Follow this and additional works at: https://knowledgecommons.popcouncil.org/departments_sbsr-rh

Part of the Family, Life Course, and Society Commons, Gender and Sexuality Commons, International Public Health Commons, and the Women's Health Commons How does access to this work benefit you? Let us know!

\section{Recommended Citation}

Khan, M.E., John Townsend, Ranjana Sinha, and Seema Lakhanpal. 1997. "Sexual violence within marriage: A case study of rural Uttar Pradesh," Asia and Near East OR/TA Project Special Report. New Delhi: Population Council. 


\section{Sexual Violence Within MaRRiage}

\section{A Case Study of Rural Uttar Pradesh}

M. E. Khan, John W. Townsend, Ranjana Sinha and Seema Lakhanpal

Paper prepared for Annual Meeting of

APHA 1997 held at Indianapolis, USA November

9-13, 1997

\section{Population C ouncil \\ New Delhi, India}




\title{
SeXual Violence Within MarRiage A CASE Study OF RURAL UtTAR PRADESH
}

\author{
M.E. Khan*, John W. Townsend*, Ranjana Sinha* and Seema Lakhanpal*
}

Till recently the study of sexual behaviour, despite being a very important area of human behaviour, has remained an untouchable subject. The sensitivity of the subject and difficulties in collecting required information were added discouragement for the socialscientist to venture in this area of human behaviour. However, the advent of AIDS and its rapid spread in India has changed the scenario. Today the study of sexual behaviour is an important subject and both national and international agencies, as part of AIDS control programme are encouraging research on the subject. However, still very few studies are available on the subject (for detailed literature review see Nag, 1996; IJSW, 1994). Few which are available address more to those who are at risk, e.g. commercial sex-workers and their clients, truck drivers. Studies on sexual behaviour of the general population, particularly those in rural areas are rare. Issues like sexual violence are still more neglected. The present paper addresses a totally neglected area, i.e. sexual coercion within marriage.

\section{Data}

This paper is based on a detailed qualitative study carried out by the Centre for Operations Research and Training (CORT) on the decision making process involved in seeking abortion. The study was carried out in two villages of Lucknow district located in central Uttar Pradesh. The villages were about 15-17 kms. away from Lucknow city, the capital of Uttar Pradesh. Both the villages were easily accessible by bus as well as other mode of transportation. One of them were large village with about 6500 population while the second was relatively smaller (2000 population).

Data was collected by two trained social scientists, who spent about 5 months in the field using various qualitative approaches - indepth case study, focus group discussions with community members and several informal interviews with health and abortion service providers. Detailed data was collected on unwanted pregnancy, abortion seeking behaviour, contraception and sexual behaviour including sexual abuse. During the study period, a total of 122 currently married women were informally interviewed several times. Out of these 122, 115 answered questions on sexual behaviour. On average each woman was visited five times and the total time spent with each of them ranged between 8-10 hours. Data on sexual behaviour including frequency of intercourse and sexual violence was collected in the last phase of the field work when the social scientists had developed

\footnotetext{
* The Population Council, New Delhi

** Centre for Operations Research and Training (CORT)
} 
good rapport with the informants. Details of selection of women and methodological issues including problems encountered during data collection, particularly on sexual behaviour and insight developed from the field on managing such situations are discussed elsewhere (CORT, 1996).

\section{Findings}

It was surprising to note that once the women were taken into confidence and we started talking in their "code" language, getting information on sexual matter was not as difficult as generally it is assumed. However, understanding and speaking of their 'code words' are critical for a smooth and easy conversation on sexual behaviour. For instance, despite of our good rapport with them, initially we could not understand their answers to our questions on sexual relationship. For example when we tried to assess frequency of sexual relationship which generally they had with their husbands, we received reply in the following words:

\section{"Hum roj nahi bolthe hai. Hum log mahina mai dho-char din hi bolthe hai."}

Literary translation of this would be "we do not talk everyday. We talk only two to four times in a month." Here the word 'talk' was their code word for intercourse. Similarly a women explaining reason for discontinuing IUD had said:

"Hum ko bath-cheet karene mai dikkat hoti thi" (During my talk I was facing problem).

Here 'bath-cheet' which is another Hindi word for talking/discussing was used as code for sexual relationship. Once we understood it, it was easy for us to ask them whether yesterday they had 'talked' with their husband and we generally received the answers without much hesitation on their part.

Out of the 122 women informants, 98 answered all questions related to their sexual behaviour, 17 answered partially while only 7 totally refused any discussion on sex. Analysis of the characteristics of those who answered fully, partially or refused to participate in the study, did not reveal any specific pattern. It depended on the situation when the woman was approached, who was present at that time, or what work she was doing. It is important to point out that complete privacy was not always required to discuss the subject. In contrast we found that sometimes discussion was easier and more interactive when two or three women were present together. It was the relationship and closeness among them which mattered. In the presence of the husband, mother-in-law or other senior family member, any discussion on sexual matter was, however, very difficult. In fact, when husband was at home, often the informants did not even like to entertain our visit to their household. In such occasions, generally we were told "behen baad me ana" (sister come after sometime) (CORT, 1996). 
Before asking women about sexual coercion within consensual union, we had detailed discussion with each of them on their sexual practices at different stages of their married life. Usually it started with discussion on whether the women at the time of their marriage had knowledge about sex, and to what extent they were mentally ready to enjoy sex with their husband. Subsequently, questions were asked on their first sexual experience, frequency of intercourse, reaction to their first pregnancy and so on. In this paper information related to sexual coercion have been analysed and presented.

\section{Beginning of Sexual Life}

The analysis showed that in most cases (103 out of 115) gauna took place only when they started menstruating. In few cases (12) though the gauna took place even before menstruation, they did not live together with their husband. Either they slept with her mother-in-law or went back to her parents house after living in the in-law's house for a brief period and returned only after menstruation.

A 29 year women who got married at the age of 6 and her gauna took place at the age of 12 years said:

"After gauna I had come here (in-law's house) only for one day. Then again I came here after one and half year to stay with my husband. By that time my mahwari (MC) had started."

Another 32 year old informant said:

"My gauna was done when I was only 12 years old and had not started menstruation. At that time I came to my in-law's house only for one week. During those period all the time I stayed with my mother-in-law or other women in the family. I had no contact with my husband. I returned to this place (in-law's house) after two years when my mahwari (MC) started.

Table 1: Knowledge of women at the time of their gauna about sex and reproduction

(Percent)

\begin{tabular}{|l|c|c|c|}
\hline \multirow{2}{*}{ Reproductive knowledge } & \multicolumn{3}{|c|}{ Did women had knowledge } \\
\cline { 2 - 4 } & $\begin{array}{c}\text { Yes, but } \\
\text { vague }\end{array}$ & No & Total N \\
\hline Sex life which takes place after marriage & 18 & 82 & 115 \\
\hline How a woman becomes pregnant? & 4 & 96 & 115 \\
\hline How a woman delivers a child? & 4 & 96 & 115 \\
\hline
\end{tabular}


Though most of them reported having periods before gauna, few understood its relevance to marriage and child birth. In the words of Rukmani, a 21 year old illiterate Yadav woman:

"I was married when I was only 13 years old. My period started just a day before my marriage took place. I did not know what was happening to me, when I saw the bleeding, I got very scared and started crying and told my mother...... No, how do I to know how it was related to marriage or pregnancy. Nobody told me either".

The study reveals that at the time of marriage, girls generally have little knowledge about sex life, pregnancy and delivery. For instance none of the 115 women interviewed had a clear knowledge of the sex life which takes place after marriage, only 18 percent had some vague idea (Table 1). Narrating her experience Rani, a 32 year old illiterate informant with four children said:

"First time when I came in contact with my husband, I was not knowing anything about sex. I was sleeping with my jethani (wife of husband's elder brother), when she went left the room and sent my husband in. I was embarrassed and just ran away to my mother-in-law. Then both my jethani and sister-in-law pushed me into the room by force and shut the door from outside".

Similarly Laxmi, another informant (32 years) married at the age of 13 years, knew nothing of sex life that takes place after marriage. The first sexual experience came as a blow - she never thought marriage was going to be so different from the gauna of "guddaguria shadi' (doll's marriage) she played among friends. She recalled:

"It was a terrifying experience, when I tried to resist, he pinned my arms above my head. It must have been so painful and suffocating and I must have fainted for I only remember getting up in the morning and finding stains of blood on the sheet. My husband was no longer in the room. I slowly got up to go the toilet, feeling sick. While I was urinating, I experienced pain and terrible burning sensation."

Other first person accounts given below reveal, how many informants expressed their feeling of experiencing sex in the absence of prior knowledge about sexuality. Sundari, 33 year old Thakur woman with four years of schooling said:

"When I experienced it first time I was not knowing anything. I was very 
nervous and began crying that what it is happening." 
Almost same feeling was expressed by Ragini, 34 year old woman with two children:

"When I came in contact with my husband then only I discovered everything. That day I cried a lot. It was very painful, but what could I do? I could not go any where and also I could not tell him anything. He did whatever he wanted."

Ramvati, 19 years with education upto 7th class, narrated her experience:

"Yes I had a vague idea about the sexual relationship. My 'bhabhi' told me a little about it before my gauna. She said that this was an inevitable part of a man-woman relationship after marriage. She also advised me to do whatever he says and that I should not say 'no' to him any time. I would say that my bhabhi had tried to prepare me mentally about the things which happens after marriage. Still I felt so embarrassed. It was painful and I hated it. He was brutal too. I cried a lot when he left the room."

Our informal discussion with the women revealed that at the time of marriage twothird of them (76 out of 115) did not know anything about sexuality. While the rest had some vague knowledge from their friends, bhabhi and books. Most of them learned about sex life only by personal experience. On probing that before marriage did not anybody inform you about sex life, most of them answered negatively and as their answers indicate most of them were mentally not ready for the experience. Rupa a 19 year illiterate woman from Yadav community said:

"Today is the first time you are asking this type of questions, before this nobody asked or informed anything regarding this."

A 34 year illiterate Harijan woman with 5 children said:

"Nobody had informed us anything. When time came, God taught us everything"

Kunti Devi a 35 year old middle aged woman said:

"Who could have prepared me for marriage and things that happened after that? I do not think it would have even occurred to my mother. She taught and explained me about cooking, sewing, cleaning etc. but never these things. She must have thought I would learn it myself as she must have learnt herself through experience." 
Some of the informants (23 out of $115 ; 20$ percent) reported that the first person who informed them about sex life was their husband. As Rajkumari recalled:

"My husband explained me about the relationship between husband and wife. I do not remember the actual wordings but he explained me that after marriage husband and wife have to live together. He showed me few photographs, how husband and wife live together. He showed me a book also, but because I am illiterate I could not read. He read and explained some of these things. Initially it was very embarrassing for me. I just kept quite."

The analysis thus revealed that very few women had knowledge about sexuality or sexual life which follows after marriage. In small number of cases (about one-fifth) husband turned out to be the only source who tried to inform and perhaps prepared them for sexual experience. Otherwise in majority of the cases their first sexual encounter with their husband was not of love and affection, but of power where they had to give whatever their husband wanted from them. For most of them, who were very young girls in a strange place where they did not know anybody, their first sexual experience was scaring and instrumental in making them submissive to their husband's wishes. Many felt that despite of the trauma they experienced, they were not in a position to resist their husband's sexual coercion. According to them it was the only way they could get the closeness and support of their husband, in an in-law's house which is traditionally known for being difficult and demanding of daughters-in-law.

\section{Frequency of intercourse}

Of the 122 women who answered questions on sexual behaviour 114 provided information on the frequency of intercourse they generally have in a week. Initially we faced some hesitation before getting the required information. A few typical remarks include "you are asking too many useless questions, who keeps a count on it". However, finally they opened up and many answered in their "code" words discussed earlier. For instance a 19 year old young woman said,

"Woh to roj he 'bat-cheet' karna chahte hai, lakin hum nahi. phir bhi hafta me char bar to ho hi jata hai. He (husband) wants sex every day but I do not, still it happens four times a week.

The analysis revealed that young women aged 15-20 (or those who were married for less than 5 years on an average had intercourse 3-4 times a week. It declined with age as it dropped to 1-2 times a week for women aged 26-30 and 31-35, but interestingly it increased again to 2 per week for women aged 36 years and more. Probing revealed that 
older husbands, who often are less busy in work, seek more frequent sexual relationship. Refusal to sex and sexual coercion

Getting information on sexual coercion was still more difficult and has been narrated in detail elsewhere (CORT, 1996). For instance an informant aged 28 years who had earlier provided considerable information on her sexual experience commented:

"Haven't you already asked me enough? "I am feeling shy in answering, aren't you shy in asking such questions?"

Yet another 26 year old educated (who had studied up to class 8) Brahmin informant commented:

"Don't talk about these things in village. Nobody is going to answer you on these issues as all this (shamelessness) goes on only in the city, not here"

However, after persuasion, probing and several visits out of 115, 98 women answered our questions. Analysis of these answers showed frequent sexual abuse by their husband. For instance out of 98 who answered all questions, 67 (68 percent) reported sexual coercion -- 21 percent reported physical violence, 14 percent reported anger, while the remaining 32 percent though reported sexual coercion by their husband, did not give any further details. Most of the women (70 percent) could not resist their husband and submitted to his demands (Figure1). However, about one-third women did not report any coercion by their husband. 


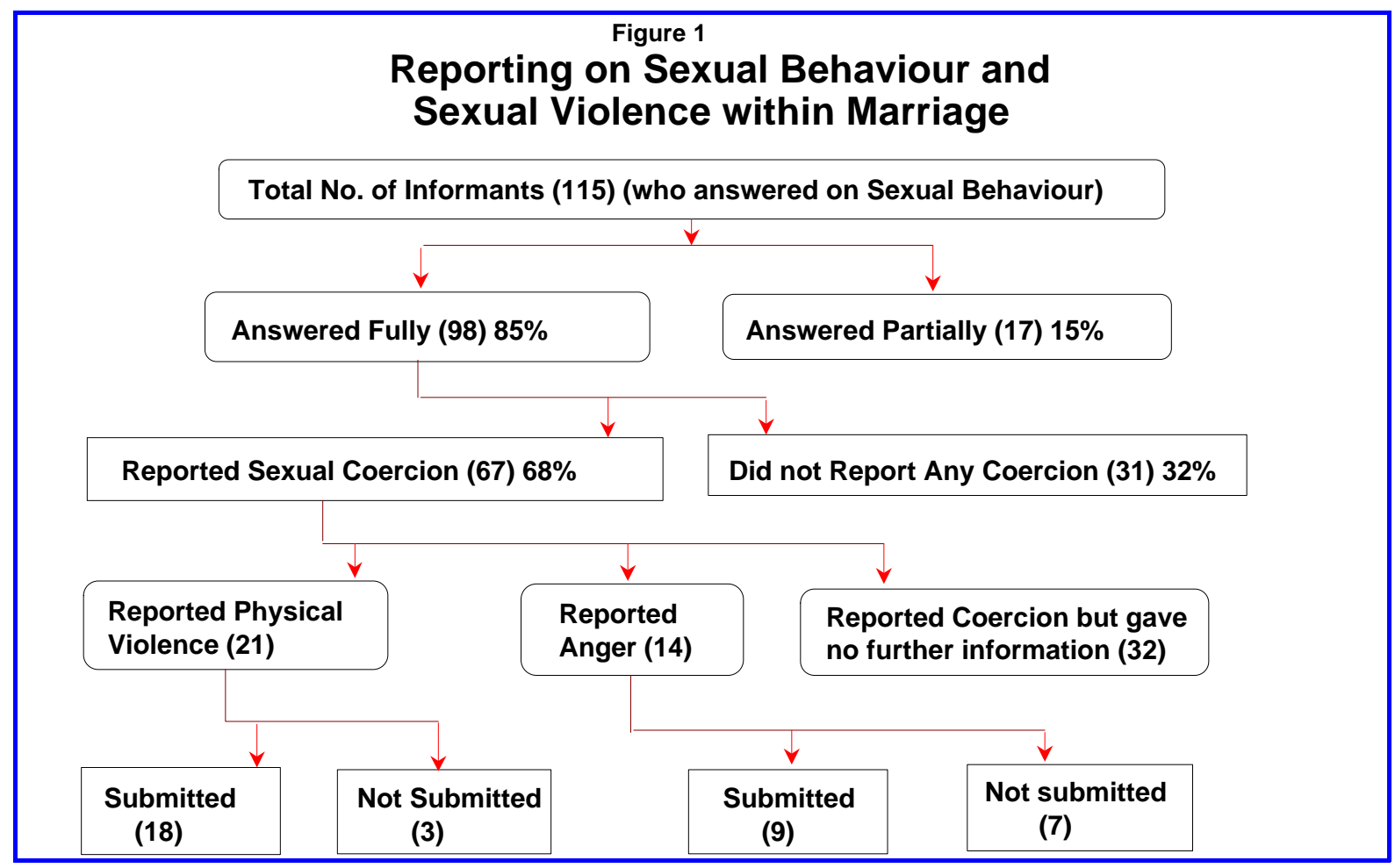

A few women reported their sexual encounters, not only as traumatic, unwanted or forced, but also as 'rape'. For instance, Girija, who had a difficult and forced sexual encounter with her husband at a very young age (13 years) commented:

"Nobody would call this a normal sexual encounter. It can only correctly be labelled as 'rape' by her own man. Even now when it comes to sex, at time he gets violent when I resist or refuse to his sexual demands. He warns me, I will go for a second marriage. I tell him; 'alright, it would be good for me also to get rid of a man like you - but I 'll see to it that I also get my fair share of the property. Yet in the end he finally gets what he wants."

Indrani, a 40 year old illiterate woman, expressing her helpless state said:

"What could I do to protect myself from these unwanted pregnancies unless he agrees to do something? I feel so helpless. Once when I gathered guts and told him I wanted to avoid sex with him, he said what else have I married you for? He beats me for the smallest reasons and have sex whenever he wants. I never had the guts to put forth my wish to him again. Then I thought, after all wasn't I born for this purpose? It is my duty to serve my husband and that is all that I should remember".

Rampati, a 26 year old Paasi woman who got married at twelve and half years said: 
"How could a twelve and half year old child enjoy that (sex)".

Rampatis' sexual initiation was like an assault that has left her scared by a permanent sense of trauma. Talking about her present sexual life she said:

"Of course there is violence when it comes to that. He has thrashed me, slapped and abused me several times when I refused to have it with him. He said, when I'll have the urge, where will I go? Do you want me to go out, to someone else? What can I say after this? This is the last thing I would want. Look, (pointing towards her knees) just yesterday he beat me so hard that my knees are still hurting. I had refused to have sex with him. I told him I wasn't liking it at which he said would you like to have it with someone else, if not with me?"

Says Mita, a 25 year old, illiterate woman relates:

"He gets angry when I refuse - but in the end I always agree. No, it doesn't reach the degree of violence." 
Shanti, a 17 year old informant said:

"No, he never beats me but sometimes abuse me saying "What else did I bring you here for? Why did you marry at all? If you do not want to do it with me then go to your parents house. At last I would submit."

A number of recent studies collaborate the above observations. For instance 77 percent of the women interviewed in Delhi slums reported that on a number of occasions their refusal to satisfy the sexual desire of their husbands lead to conflicts -- 33 percent reported forced sex, 27 percent were abused, while 9 percent reported physical violence. Interestingly, when the same question was asked to men, while 33 percent admitted refusal of sex by their wife, only 9 percent reported forced sex or beating of their wives (CORT 1997).

A large male reproductive health survey recently carried out in Uttar Pradesh (Evaluation Project, 1997) also revealed that almost three out of every ten husbands reported having had sex when the wife was not willing. The study also reported that almost 23 percent husbands had physically forced their wives to do so. For sex using physical force was more common in rural than urban areas and among younger couples (i.e., husband under 30 years or age) than those had 3 or more children.

\section{Mechanisms used to resist and avoid submission to sexual abuse}

While a majority of women submit to their husband's wish, 30 percent are generally able to resist sexual coercion by their husbands. The mechanisms used include:

- Threat to start screaming, endangering his prestige.

- Threat to commit suicide if forced to have sex.

- Waking up young children who generally sleep with them.

- Reporting false or prolonged menstruation periods.

The following verbatim accounts give the dynamics of interaction which takes place in such situations.

Guddi, 19 years old, who has studied up to 8th class, and who experienced three pregnancies said:

"No he is not violent in nature but when it comes to that (sex), he does not agree even on my refusal. He scolds me; if you do not want it, I do. Only three days back he slapped me for that. I did not want that. I am always afraid I would get pregnant." 
In the words of 18 year old Rohini, who has passed high school:

"When I refuse sex to him he gets abusive, slaps me, shakes me hard. At times he says, what good are you? If you can't do this much for me, get out of this house. I will go for second marriage. Sometimes I agree but many times I did not agree and in such a situation, I warn him, I will kill myself if you do this forcefully. I will take poison. At this he gets afraid that if it actually happened, the blame would go on him."

A 21 year old woman, educated up to class 3 said:

"When I try to resist, he hits me with whatever comes in his hand. But when I say "If I start yelling and screaming, what respect will there be left for you? At this he leaves me. He wouldn't do it at the risk of his reputation."

Similarly a 25 years old, illiterate Lodh (Scheduled Caste) woman said:

"He gets angry, but can't force now. Whenever I see what he's up to and I am not in a mood, I wake my child up. As it is, I make him sleep between us. What can he do? Earlier when he used to force, I couldn't do anything."

According to a 30 year old illiterate Thakur woman:

"Sometime I stop him by giving excuse that I am having a prolonged menstruation. He just gets angry and leaves me alone but sulks and doesn't talk for days."

Malti, a 23 year old illiterate women said:

"If I know that in next one or two days my period would start during those days instead of saying 'no' to him I just tell him that my period has started. Sometimes I tell him my period still continuing. I know he does not like it but he keeps quiet."

The same thing was reported by Usha, a 25 year old illiterate Dhobi woman:

"He gets angry but doesn't force. However, sometimes he doesn't come home for two-three days".

Generally refusal and not yielding to husband's coercion comes from relatively younger women, but not before having spent a few years (3 or more years) of married life. In the initial stage of their married life, they were as helpless as any other women.

\section{All Did Not Report Sexual Coercion}


As indicated earlier, about one-third of the women did not report any sexual abuse by their husband. Generally their comments where as follows: "we have understanding" or "no he does not force".

According to one of the informants age 23 years:

"Sometimes when I do not have the mood, I tell him I do not want this time. Generally he ask a few questions 'what happened?' or 'Are you alright?', but then he never force it."

It would be interesting to further analyse the profile of men who were reported to be better behaved with their wives. Similarly, it will be also important to analyse the profile of women who reported no sexual violence by their husbands. Such analysis may show some patterns having programmatic significance.

\section{Discussion and Conclusion}

This preliminary analysis of sexual coercion within marriage brings out many important findings. First, most of the girls at the time of their marriage have no knowledge about sexuality and the family formation process. Because of this, they are not prepared mentally for the sexual life which suddenly starts after marriage. Often it is shocking for them and has adverse psychological consequences. For many, sexual union becomes repulsive and remains only a means of enjoyment for their husbands.

The study also reveals frequent sexual coercion within marriage. Husbands take as their 'right' to have complete control over the body and sexuality of their wives. The prevailing social structure and value system supports and perpetuates this assumed 'right' and is well reflected in the comments of the informants, who feel that is their role as wife is one of resignation. In fact, the subordinate position in society to which the women have been subjugated for centuries has not only suppressed their self esteem but also has conditioned their thinking process. It is well reflected in two recent studies when the women were asked whether wife beating for refusing sex is justified, 15-30 percent women answered in affirmative (CORT, 1997).

Violence could result if women refuse to submit to the sexual desire of their husbands. This study also contradicts the general belief that women are subjected to sexual violence and rape largely by strangers or 'outsiders'. The study shows it is the insiders - their own husband who are the main perpetrators of sexual coercion and abuse. It certainly also works as a mechanism to keep the women submissive to their husband's wishes.

Yet another observation is that often women's resistance to sex, and the resultant sexual violence, starts from their fear of unwanted pregnancy. According to the present study, most of the women had experienced two or more unwanted pregnancies (CORT, 
1996). Limited accessibility of women to safe and effective contraceptives, coupled with their lack of control over sexuality, exposes them to unwanted pregnancies and higher rate of maternal morbidity as well as mortality arising from pregnancy complications.

Refusal of sex could also be the reflection of women's desire to assert some sense of autonomy and pride in themselves. Though it did not clearly come out from their statements, yet it could be assumed as the refusal to sex and particularly not submission to the sexual desire of their husbands, generally came from younger and literate women. Further studies are required to understand the motivation and psychology and dynamics behind such sexual interaction/behaviour.

A schematic diagram of the dynamics of sexual violence within marriage bound, emerging out of this study is presented in Figure 2. It is well appreciated that these observations are very preliminary and further investigations are required to test the validity of these linkages. A major limitation of this framework is lack of understanding of men's sexual behaviour and the psyche under which they operates and make them violent. An equal important aspect is to understand the changes which are taking place from men's perspective and its influence on their sexual behaviour.

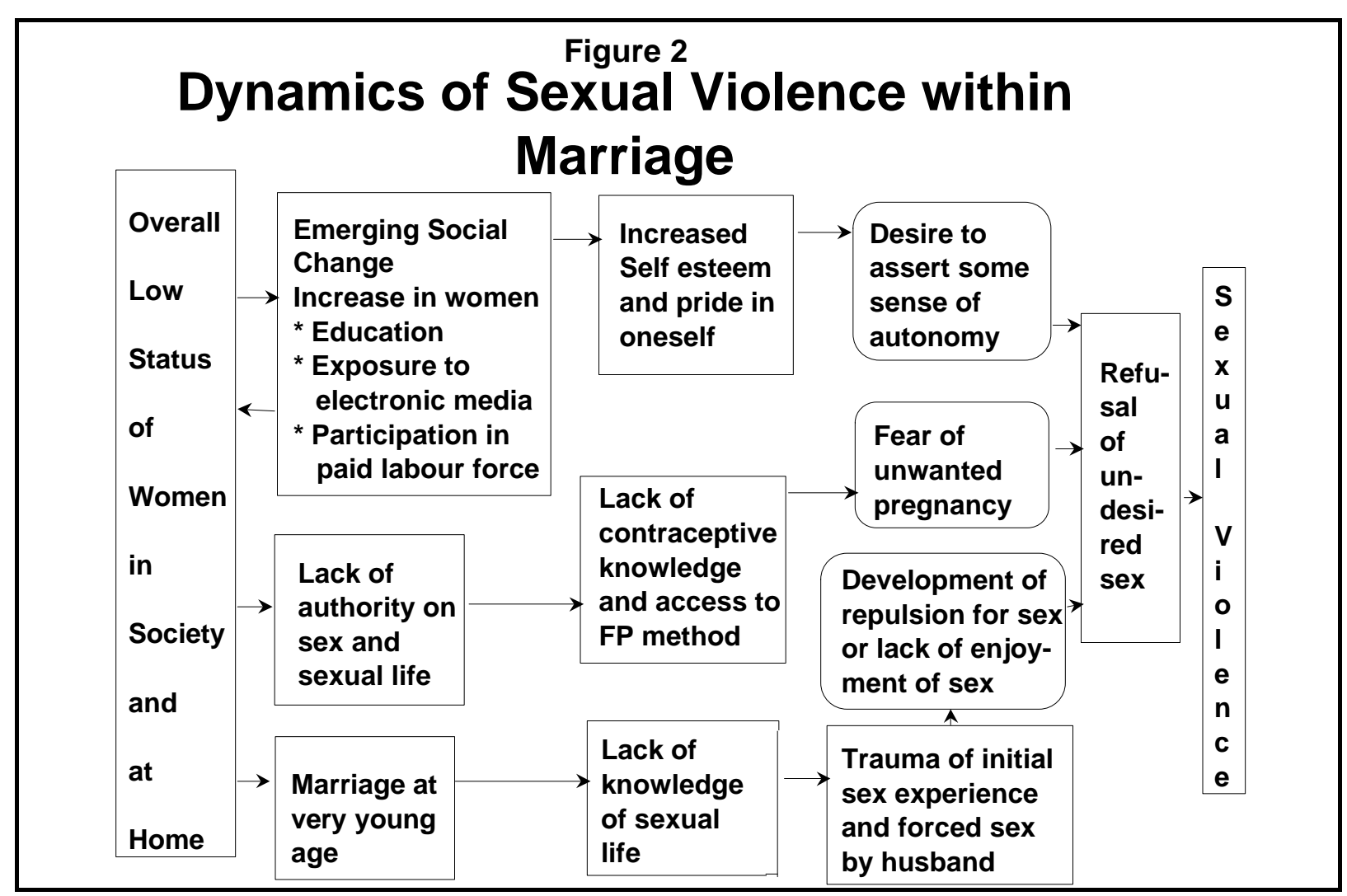


Systematic and persistence advocacy and remedial measures are required to address the drudgery and violence women face in their own families and society. No single intervention can change the situation unless a well conceived plan of action addressing the socio-economic and legal rights of women is developed and implemented. Education of women, educational campaign to inform women about their rights and legal protection, and a sustained effort to sensitize men to bring about gender equality would contribute significantly in reducing such sexual violence. To carry out such programme demands both resources and political commitment.

In the short term, however, some immediate initiatives may be taken to reduce the drudgery of women. The first and perhaps the most important, would be introduction of family life education through different channels and forums; both formal and informal, to sensitize both the adolescent boys and girls about gender equality, need of communicating among partners, sharing responsibilities and prepare them about their married life and contraception. Such an education would go a long way in reducing the trauma which young girls often experience immediately after marriage and subsequently in their life. This may also helps in reducing their repulsion against sexual relations which some of them develop after their initial 'shocking' experience. Proper orientation on gender issues, rights and duties of family life and reproduction could make sexual life enjoyable to both the partners than perceiving it only as a mean for male's enjoyment. It could also save them from various worries related with first pregnancy and delivery of the child.

Similarly, interventions aiming to increase accessibility of women to safe and effective contraception, and helping them to protect themselves from unwanted pregnancies would at least reduce some of their drudgery and help them to enjoy a safe sexual life. It may even help marginally to reduce sexual coercion as refusal to sex because of the fear of unwanted pregnancy will also decline. However, here it is important to underline that fear of unwanted pregnancy is only one of the causes for refusing sex by women. Other possible causes such as using it as an expression of assertion for their sense of autonomy and pride or expression of frustration and anger, could be addressed only by bringing about better gender equity and involving men as responsible partner.

\section{References}

CORT, 1996. "Methodological considerations in doing research on sexual behaviour and reproductive health". Working paper No.7, Centre for Operations Research and Training, Baroda.

CORT, 1996. "Decision making process in seeking abortion - A case study of rural Uttar Pradesh, Draft report. Centre for Operations Research and Training, Baroda.

CORT, 1997. "Knowledge, Attitude, Behaviour and Practices of the Community Members on Sexuality and STD/AIDS in Slums of Delhi. Monograph. Centre for Operations Research and Training, Baroda.

CORT, 1997. "Knowledge, Attitude and Practice of Men and Women on Sexuality and Reproductive in Rural Gujarat. Draft Report. Centre for Operations Research and Training, Baroda. 
Indian Journal of Social Work, 1994. Special issue: Sexual Behaviour and AIDS in India.

Nag Moni (1996), Sexual Behaviour and AIDS in India. Vikas Publishing House Pvt. Ltd. Delhi.

The Evaluation Project, 1997. Uttar Pradesh Male Reproductive Health Survey - 1995-96. The Evaluation Project, Carolina Project Centre, UNC. 